\title{
Gêneros orais no ensino fundamental: uma reflexão a partir de um liuro didático
}

Oral genres in elementary school: a reflection from a textbook

Ana Paula Elsner

Universidade de Santa Cruz do Sul - UNISC

Luane Guerra Vitorino

Universidade Federal de Santa Maria - UFSM

DOI: https://doi.org/10.5902/2176148538806

Resumo: $O$ presente artigo objetiva analisar o tratamento da oralidade em um livro didático (LD) de Língua Portuguesa (LP), da coleção Português Linguagens da editora Saraiva, triênio 2017, 2018, 2019, de autoria de Willian Roberto Cereja e Thereza Cochar Magalhães, apresentada no capítulo destinado à modalidade oral. Nossa metodologia é analítico-reflexiva e nosso resultado sinaliza que o livro em questão está em desacordo com os documentos oficiais, pois refere-se aos gêneros orais de forma muito restrita, tendo em vista que apresenta somente um capítulo sobre o gênero oral seminário.

Palavras-chave: Oralidade. Gênero oral. Livro didático de Língua Portuguesa. Seminário.

Abstract: This article aims to analyze the treatment of orality in a didactic book of Portuguese Language, from the collection Português Linguagens of the publisher Saraiva, triennium 2017, 2018, 2019, authored by Willian Roberto Cereja and Thereza Cochar Magalhães, presented in the chapter for the oral modality. Our methodology is analyticalreflexive and our result indicates that the book in question is in disagreement with the official documents, because it refers to oral genres in a very restricted way, considering that it presents only a chapter on the oral genre seminar.

Keywords: Orality. Oral genre. Portuguese-language textbook. Seminar. 


\section{Considerações iniciais}

Considerando o ensino atual de Língua Portuguesa, entendemos que a oralidade é uma prática essencial para o desenvolvimento dos alunos, tendo em vista a relevância do domínio da prática oral pública. Inúmeras situações necessitam de um bom rendimento comunicativo e, poucas vezes, os estudantes estão capacitados para um bom diálogo, Ana Paula para uma entrevista, um seminário, a apresentação de um trabalho, etc. Elsner Incluir a oralidade em sala de aula significa estimular a criticidade, a reflexão, a leitura, e tantos outros aspectos mais específicos, como: in-

Luane Guerra Vitorino terlocução, escolha lexical, postura adequada, respeito à fala do outro.

De acordo com Bueno e Costa-Hubes (2015), a atividade mais recorrente na escola, quando se refere à oralidade, ainda é a oralização da escrita. Além disso, as autoras afirmam que o trabalho com gêneros não é aprofundado, sendo que a maioria dos livros discute a função temática e não a sua composição, perdendo, assim, a compreensão das características de cada gênero textual.

Em uma pesquisa no Portal de Periódicos da CAPES/MEC ${ }^{1}$, buscamos artigos e teses que versassem sobre os gêneros orais na escola e, em especial, nos livros didáticos de Língua Portuguesa. Com isso, buscamos pelas palavras-chave: "gêneros orais na escola", "gêneros orais em livros didáticos de Língua Portuguesa" e "oralidade nos livros didáticos". Em suma, de acordo com a pesquisa "gêneros orais na escola" foram encontradas oito teses, sendo quatro destas voltadas para o trabalho com o gênero oral nas aulas e em livros de Língua Estrangeira (LE); uma tese, que tratava sobre produção de material didático para o desenvolvimento da compreensão oral, sendo esta de Portugal. Já na pesquisa por "gêneros orais em livros didáticos de Língua Portuguesa", obtivemos 19 resultados, entre teses, livros e artigos, dos quais nenhum foi coerente com a busca, pois verificamos que a oralidade era utilizada apenas como pretexto para o trabalho com o texto escrito.

Sendo assim, neste artigo, propomo-nos a analisar como a oralidade é trabalhada no livro didático de Língua Portuguesa, da coleção Português Linguagens da editora Saraiva, triênio 2017, 2018, 2019, de autoria de Willian Roberto Cereja e Thereza Cochar Magalhães, destinada ao $8^{\circ}$ ano do ensino fundamental. Adotamos dois pressupostos gerais: $\mathrm{o}$

1 Disponível em: <http://www.periodicos.capes.gov.br/>. Acesso em: 25 de mai. 2019. Não descartamos a disponibilidade, em outras plataformas de pesquisa e/ou impressos, haverem outros artigos, teses e livros que versem sobre as palavras-chave. 
primeiro refere-se a um breve histórico do livro didático e sua relevância no contexto educacional brasileiro. $O$ segundo trata da relevância do trabalho com os gêneros orais na escola.

Nossa metodologia é analítico-reflexiva. Escolhemos o terceiro capítulo da obra didática, referente ao gênero oral "seminário", e pontuamos algumas reflexões a respeito da oralidade no livro.

$\mathrm{O}$ texto está dividido em duas partes: inicialmente, discutimos a relevância do livro como uma ferramenta didática para o professor, bem como a importância do trabalho com a oralidade (principalmente, por meio de gêneros orais) na escola. No segundo momento, analisamos a obra em questão e apresentamos algumas reflexões acerca da proposta.

\section{Livro Didático: breve histórico}

Inicialmente, como nosso objeto de estudo é o tratamento da oralidade no livro didático, cabe destacar a definição de "didático", em que, conforme o dicionário "Houaiss" (2009), significa "destinado a instruir [livro d.] que facilita a aprendizagem [recursos d.]". Contudo, conforme o Programa Nacional do Livro Didático (PNLD), o livro didático apresenta caráter pedagógico, isto é, ele

(...) deve veicular informação correta, precisa, adequada e atualizada, procurando assegurar que os componentes curriculares e as áreas de conhecimento possam ser trabalhados, a partir da abordagem de temas abrangentes e contemporâneos, que contemplem diferentes dimensões da vida humana, tanto na esfera individual, quanto global, regional e local (PNLD, 2016, p. 9).

A partir desses conceitos, o Livro Didático (LD) serve para orientar o professor a ensinar seus alunos, de maneira objetiva, os conhecimentos contidos nele, direcionando os conteúdos diretamente ao aluno. Segundo Witzel (2002, p. 11) o LD é "o livro adotado na escola, destinado ao ensino, cuja proposta deve obedecer aos programas curriculares escolares".

Os assuntos relacionados ao LD são de responsabilidade do Fundo Nacional de Desenvolvimento da Educação (FNDE), que é encarregado de três programas, conforme o site do Ministério da Educação (MEC): o Programa Nacional do Livro Didático (PNLD), o Programa Nacional do Livro Didático para o Ensino Médio (PNLEM) e o Programa Nacional do Livro Didático para a Alfabetização de Jovens e Adultos (PNLA). 
Ana Paula

Elsner

Luane Guerra

Vitorino

O PNLD, basicamente, apresenta um edital que pode ser acessado no Portal do Fundo Nacional de Desenvolvimento da Educação $(\mathrm{FNDE})^{2}$, em que especifica os critérios e princípios para que as editoras inscrevam suas obras. A partir disso, elas são avaliadas pelo Ministério da Educação (MEC), sendo aceitas ou não. Após a seleção das obras, o FNDE publica o Guia do Livro Didático, que tem por finalidade auxiliar, por meio de resenhas críticas, o professor quanto à escolha dos LDs. Em seguida, os professores e diretores das escolas, participantes do FNDE, escolhem os livros mais pertinentes para a sua instituição, preenchendo um guia com apreciações negativas ou positivas (FNDE, 2017).

O guia do Livro Didático, que está disponível para o professor, traz as descrições e avaliações das obras e, como referido anteriormente, apreciações de aspectos que podem ser negativos ou positivos. No entanto, o professor deve considerar, assinalando no guia, os conteúdos (todos ou alguns) em que vai aderir da obra escolhida para usar em sala de aula (SILVA et al., 2015).

o livro didático é sempre muito discutido, principalmente em relação aos aspectos metodológico, linguístico ou ideológico. Conforme Coracini (1999) os LDs, com o "advento da abordagem comunicativa" (p. 34 ), ficaram ausentes, já que os professores os evitavam e os substituíam ou complementavam com matérias avulsas, como artigos e reportagens de jornais e revistas, bulas de remédio, enfim, trabalhavam outros gêneros externos para integrar aos livros. Embora alguns professores reconhecessem as falhas dos livros, muitos deles preferiam aderir, pelo fato de que sem ele os alunos ficariam dispersos. Existe, assim, um pensamento de que o LD, apesar de suas falhas, resguarda um conteúdo que fica disponível ao aluno.

De maneira geral, os materiais didáticos são, portanto, importantes instrumentos que, se usados de maneira correta, auxiliam na busca de resultados satisfatórios no processo de ensino e aprendizagem de Língua Portuguesa (LP), por exemplo. O LD, sem dúvida, é o principal recurso para o ensino de escolas da rede pública no Brasil, tornando-se objeto, ora representativo ora polêmico, de estudo de pesquisadores. Com isso, ao questionarmos os LDs, estamos considerando também o ensino que neles está cristalizado. De acordo com, Rojo (2003, p. 87), em vista do trabalho com a linguagem oral, este ain-

2 Disponível em: <https://www.fnde.gov.br/>. Acesso em: 20 de mai. 2019. 
da se apresenta como um dos pontos de menor clareza para os autores e editores dos Livros Didáticos de Língua Portuguesa: "sobre como ensinar e como aprender".

Considerando o ensino da nossa língua materna, destacamos que, para o ensino, o desenvolvimento da linguagem oral é fundamental. Contudo, estudos demonstram que a oralidade apresenta pouquíssimo espaço em sala de aula, inclusive nos livros didáticos de Língua Portuguesa (LDP), pois o destaque é somente para o desenvolvimento da escrita. A concepção de que oralidade não é papel da escola, é equivocada, pois sabemos que existem muitas situações formais, que não são aprendidas espontaneamente.

Em vista dos LDP, destacamos a pesquisa feita por Cruz (2012), em que analisa 16 coleções de livros de Língua Portuguesa do $6^{\circ}$ ao $9^{\circ}$ anos aprovadas pelo PNLD-EF/2011. $O$ autor afirma que a maioria das atividades propostas eram referentes a debates, seminários e entrevistas, porém destaca a quantidade de atividades de oralização e de simulação de fala, como relato, reconto, não sendo devidamente sistematizadas. Em resumo, Cruz (2012) conclui que o trabalho com os gêneros textuais orais se caracterizam em oralização de textos escritos e resposta oral para as perguntas de interpretação de texto.

Percebemos que a negligência do trabalho com a oralidade está em desacordo com o que propõe os documentos oficiais, como os Parâmetros Curriculares Nacionais, doravante PCN's, sobre o trabalho com a linguagem oral:

(...) cabe à escola ensinar o aluno a utilizar a linguagem oral no planejamento e realização de apresentações públicas: realização de entrevistas, debates, seminários, apresentações teatrais etc. Trata-se de propor situações didáticas nas quais essas atividades façam sentido de fato, pois é descabido treinar um nível mais formal da fala, tomado como mais apropriado para todas as situações. A aprendizagem de procedimentos apropriados de fala e de escuta, em contextos públicos, dificilmente ocorrerá se a escola não tomar para si a tarefa de promovê-la. O ensino de língua materna que está sendo orientado prevê domínio de ambas as modalidades linguísticas, pois o seu ensino não se resumirá mais às abordagens das produções escritas (PCNs, 1998, p. 25). 
Sendo assim, é sobre esse universo que discute o ensino de gêneros orais, nos livros didáticos, e sua aplicabilidade nas aulas de Língua Portuguesa, no processo de interação, que pretendemos investigar. Intencionamos observar de que forma a oralidade, por meio de gêneros orais, é apresentada em um LD destinado ao ensino fundamental.

\section{Ana Paula Os gêneros orais na escola}

Elsner Com esta pesquisa, destaca-se a relevância do ensino da oralidade no âmbito escolar, pois, segundo Leal e Gois (2012) a oralidade é um eixo

Luane Guerra

Vitorino

140 do ensino que não tem sido desenvolvido, já que a escrita, geralmente, assume primazia sobre a fala no ensino da língua materna. Essa situação pode ser facilmente constatada nos Livros Didáticos, por exemplo, em que a dedicação ao ensino dos gêneros orais é de certa forma, mínima (BUENO; ABREU, 2008). Segundo Schneuwly e Dolz (2004), o ensino escolar da língua oral e de seu uso ocupam um lugar limitado, além de que os meios didáticos e as indicações metodológicas são relativamente raros.

Quando se fala em trabalho com gêneros orais, Schneuwly e Dolz (2004) consideram os gêneros orais como uma atividade pertinente, inserida no trabalho com a oralidade. Com isso, o ensino do oral pode ser desempenhado a partir de seminários, peças teatrais, debates, júris simulados, entrevistas, sendo que estes podem apresentar uma versão escrita, mas apresentam a voz como suporte (MELO; CAVALCANTE, 2007).

Nos gêneros orais existem complexidades. A primeira dela diz respeito ao fato de que a fala é emoldurada pelo modo como são pronunciados determinados sons, assim como pelo modo como o fluxo de fala é produzido, considerando pausas, entoação, qualidade de voz, ritmo e velocidade da fala. Outra complexidade diz respeito a um conjunto de linguagens que são ativadas ao mesmo tempo em que falamos: a gestualidade, a postura corporal, a expressão facial, e o direcionamento do olhar (BENTES, 2007). Considerando estas complexidades, notamos que a oralidade não pode ser considerada apenas pelas características específicas do meio sonoro, mas por outras questões epilinguísticas e extralinguísticas, que devem ser exploradas no contexto escolar.

A terceira complexidade é o fato de que há uma imbricação entre fala/oralidade e escrita/letramento, mesmo quando se pensa que estamos somente falando. No campo da oralidade existe uma vasta 
gama de práticas, gêneros e processos de produção de textos. A fala e a escrita não podem ser separadas, mas vistas em termos de um continuum de práticas e de gêneros. Em vista da fala, teríamos as conversas públicas, telefônicas e espontâneas. Já na escrita, teríamos textos acadêmicos, leis, artigos científicos, relatórios técnicos. A exposição acadêmica, as conferências e os discursos oficiais, mesmo sendo falados, estão aproximados ao campo da escrita, sendo que as cartas pessoais, bilhetes, avisos, mesmo que escritos, estão mais próximos da fala. Com isso, temos explícita a influência de práticas da escrita na oralidade (MARCUSCHI, 2001).

Outro modo de considerar a relação do oral e da escrita seria pensarmos na relação entre gêneros primários e secundários. Para Bakhtin/Voloshinov (1982 [2000, p.281] apud DOLZ; BUENO, 2015,

Gêneros orais no ensino fundamental p. 120) os gêneros primários aparecem em comunicações espontâneas do dia a dia, enquanto os secundários em situações culturais, mais complexas, como romances ou artigos científicos, que seriam da categoria escrita. De acordo com Dolz e Schneuwly (1998 apud DOLZ; BUENO, 2015) não se pode adotar uma visão simplista de igualdade entre gêneros orais aos primários e gêneros escritos aos secundários. Esses teóricos defendem que teremos gêneros orais primários e secundários, variando sua complexidade de acordo com a situação de comunicação. Por exemplo, um diálogo pode ser primário e um discurso de formatura secundário (DOLZ; BUENO, 2015). Ou seja, são essas questões, mais aprofundadas sobre os gêneros orais, que precisam ser trabalhadas na escola. É preciso distanciar a ideia de que a oralidade é apenas o espaço da espontaneidade, da manifestação do cotidiano, bem como a escrita como o espaço da formalidade. Existem diferentes níveis da comunicação oral, inclusive as mais formais, que precisam estar presentes na formação cidadã dos estudantes.

Sabemos que historicamente, a escrita sempre ocupou espaço de destaque no ensino de Língua Portuguesa, sendo a oralidade negligenciada a atividades de oralização da escrita ou simples "leitura em voz alta". Embora as duas modalidades apresentem características diferentes, não há razões para alimentarmos diferenças estanques, tendo em vista que, se considerarmos o uso da língua nas práticas sociais e em ações cotidianas, encontraremos mais relações de proximidade do que de separações: 
Ana Paula

Elsner

Luane Guerra

Vitorino

142

[...] não há razão alguma para desprestigiar a oralidade e supervalorizar a escrita. Também não há razão alguma para continuar defendendo uma divisão dicotômica entre fala e escrita nem se justifica o privilégio da escrita sobre a oralidade. Ambas têm um papel importante a cumprir e não competem. Em suma, oralidade e escrita não estão em competição. Cada uma tem sua história e seu papel na sociedade (MAR-

CUSCHI, 2007, p. 15).

Em suma, as duas modalidades merecem ser valorizadas de acordo com as suas especificidades, considerando que ambas fazem parte do mesmo sistema linguístico. O ideal é que fala e escrita sejam incluídas no ambiente escolar e, cabe ao professor, estabelecer relações a partir dos aspectos contextuais de cada modalidade.

\section{Corpus e metodologia}

O corpus escolhido para a análise neste artigo é o terceiro capítulo da Unidade 4, do livro Português Linguagens, do $8^{\circ}$ ano do ensino básico, triênio 2017, 2018 e 2019, dos autores William Cereja e Thereza Cochar. O livro possui quatro unidades: Unidade 1: Humor: entre o riso e a crítica; Unidade 2: Adolescer; Unidade 3: Consumo; e Unidade 4: Ser diferente. Cada unidade possui três capítulos.

Como já referido anteriormente, analisaremos o terceiro capítulo da Unidade 4, intitulado Sociedade Plural, especificamente, nas páginas que contemplam o gênero oral, inserida na sessão Produção de texto. 0 gênero oral abordado no capítulo 3, e único gênero em destaque no livro, é o gênero seminário. Com isso, realizamos uma interpretação da proposta apresentada pelos autores e pontuamos algumas considerações (carências e méritos) do gênero em questão.

\section{Análise}

O capítulo três da unidade quatro, intitulado Sociedade Plural, apresenta um único tópico a respeito da oralidade, nomeado Produção de texto: 0 seminário. Os autores conceituam, inicialmente, o gênero oral e sinalizam que na sequência os alunos serão orientados a um passo a passo para o desenvolvimento de um seminário (Figura 1). 


\section{Produção de texto}

\section{O SEMINÁRIO}

O seminário é um gênero oral público que pertence à família dos gêneros expositivos, como o texto de divulgação científica, o relatório, o verbete de enciclopédia, o texto didático. Comum na esfera escolar, acadêmica e profissional, o seminário pode ser realizado individualmente ou em grupo. Seu papel é transmitir conhecimentos específicos - técnicos ou científicos - a respeito de um assunto relacionado a determinada área do conhecimento.

Neste capítulo, você vai aprender a realizar um seminário.

Figura 1 - Apresentação do gênero oral: 0 seminário.

Fonte: CEREJA; COCHAR (2015, p. 250).

Gêneros orais

no ensino

fundamental

seguida, orienta-se o aluno a fazer anotações e seguir um roteiro, conforme a figura 2.

\section{Seleção e organização de informações e recursos materiais}

Selecione e organize as informações, tendo em vista os seguintes aspectos da exposição:

- como introduzir, desenvolver e concluir a exposiçāo;

- quais subtemas serão abordados no desenvolvimento;

- quais exemplos ou apoios (gráficos, dados estatísticos) serão utilizados para fundamentar a exposição;

- que materiais e recursos audiovisuais (cartazes, apostilas, lousa, retroprojetor, datashow, microfone, etc.) serão necessários.

Nesse planejamento, devem ser levadas em conta as características do público-alvo, como faixa etária, tipos de interesse, expectativas e conhecimentos prévios em relação ao tema abordado, etc. Para dar à exposiçăo um encaminhamento agradável, é importante intercalar o uso da voz com o uso de recursos audiovisuais.

\section{Produção de roteiro e esquema}

Primeiramente, redija um roteiro que permita visualizar não apenas o conjunto das informações que serão apresentadas, mas também a sequência em que isso vai ocorrer. Esse roteiro deve conter: informações-chave que orientarão seu pensamento durante a exposiçāo; indicação de recursos audiovisuais (se for o caso); textos de autoridades ou especialistas que serão citados, etc. Durante a exposição propriamente dita, deve-se evitar ler o que está escrito no roteiro, a não ser para reproduzir textualmente a citação de outro autor. Posteriormente, redija um esquema, isto é, um conjunto de anotaçōes breves que lhe servirão como apoio durante a exposição. Se necessário, você poderá olhar rapidamente o esquema, a fim de se lembrar de algum tópico ou da sequência da exposição.

Figura 2 - Seleção e organização de informações.

Fonte: Figura adaptada de CEREJA; COCHAR (2015, p. 251). 
Percebemos que neste momento a intenção dos autores é didatizar, por meio dos tópicos, a produção do gênero. Em seguida, propõe-se que os estudantes ensaiem a apresentação, de acordo com a figura 3.

Ana Paula

Elsner

\section{Luane Guerra}

Vitorino

\section{Ensaio}

Ensaie sua apresentação. Para isso, tenha à mão um gravador e o esquema. Com o gravador ligado, comece a exposição como se estivesse falando para a classe. Procure falar com segurança e fluência, evitando consultar o roteiro. Faça-o apenas em último caso. Quando terminar, ouça a gravação e avalie o resultado. Se julgar necessário, ensaie outras vezes e, se possivel, na presença de outras pessoas.

Figura 3 - Proposta de apresentação.

Fonte: CEREJA; COCHAR (2015, p. 252).

É importante destacar a sugestão do uso de um recurso (gravador) que propõe ao aluno a sua auto avaliação, bem como, o ensaio com a presença de uma plateia, o que pressupõe a tentativa de uma autonomia do estudante em relação ao aprendizado do gênero oral.

O próximo passo é efetivamente a apresentação do seminário. Nesse momento, os autores apresentam uma síntese do desenvolvimento da atividade, com a sequência dos passos a serem seguidos pelos alunos, para que o seminário tenha sucesso. Os autores alertam, também, para a possibilidade de imprevistos e alguns aspectos que podem evitá-los ou controlá-los. Entendemos que esse é o ponto principal da atividade com o gênero, pois é o momento em que os alunos irão praticar, sozinhos ou em grupos, o exercício ensaiado. Sendo assim, o tópico é apresentado com uma riqueza de detalhes e dicas aos alunos, conforme é possível ver na figura 4 . 


\section{Sequência e andamento da exposição}

1. Abertura: o professor (ou um colega) dá a palavra ao apresentador. Faz isso com palavras como "Vocês agora vão assistir ao seminário preparado por fulano...".

2. Tomada da palavra e cumprimentos: 0 apresentador coloca-se à frente da plateia, cumprimenta-a e dá início ao seminário

3. Apresentação do tema: 0 apresentador diz qual é o tema, fala da importância de abordá-lo e esclarece o ponto de vista a partir do qual irá abordá-lo. Se o tema for amplo, delimita-o, isto é, indica qual aspecto dele será enfocado. Por exemplo, se o tema é a poluição do meio ambiente, o apresentador pode delimitá-lo e tratar apenas da poluição dos rios. Esse momento do seminário tem em vista despertar na plateia curiosidade sobre o tema abordado.
4. Exposição: 0 apresentador segue 0 roteiro traçado, expondo cada uma das partes, com clareza e sem atropelos. Ao final de cada uma, deve perguntar ao público se quer fazer alguma pergunta.

5. Conclusão e encerramento: 0 apresentador retoma os principais pontos abordados, fazendo uma síntese deles; se quiser, pode mencionar aspectos do tema que merecem ser aprofundados em outro seminário; pode também deixar uma mensagem final, algo que traduza o seu pensamento ou o pensamento do grupo ou de um autor especial. No final, agradece a atenção do público e passa a palavra a outra pessoa.

6. Tempo: 0 apresentador deve estar atento ao tempo previsto e, de acordo com o andamento do seminário, ser capaz de introduzir ou eliminar exemplos e aspectos secundários, caso haja necessidade.

\section{Gêneros orais no ensino fundamental}

Figura 4 - Sequência e andamento do seminário.

Fonte: CEREJA; COCHAR (2015, p. 253).

Como apresentado na figura anterior, os teóricos apontam a sequência de instruções a fim de que o aluno desenvolva sua exposição com maior segurança. Além disso, também sugerem o uso de recursos audiovisuais como uma ferramenta para enriquecer a apresentação, o que a tornaria mais dinâmica.

Além das questões temáticas, o capítulo pontua observações em relação à postura do apresentador, como posicionamento frente ao grupo, tom de voz, ter textos de apoio e estar preparado para questionamentos. Também há considerações a respeito do uso da linguagem formal, conforme figura 5 . 
Ana Paula

Elsner

\section{Luane Guerra}

Vitorino

146

\section{Uso da linguagem}

Nos seminários, predomina a norma-padrão da língua, embora possa haver menor ou maior grau de formalismo, dependendo da intimidade entre os interlocutores. Assim

1. O apresentador deve evitar certos hábitos da linguagem oral, como a repetição constante de expressões como tipo, tipo assim, né?, tá?, ahn..., pois elas prejudicam a fluência da exposição.

2. Sempre que for necessário, o apresentador deve explicar o significado de vocábulos e conceitos específicos da área pesquisada; para isso, deve fazer uso de expressões de reformulação, como isto é, quer dizer, como, por exemplo, em outras palavras, vocês sabem o que é isso?. Deve também fazer uso de expressões que confiram continuidade ao texto, como além disso, por outro lado, outro aspecto, apesar disso.

Figura 5 - Uso da linguagem.

Fonte: CEREJA; COCHAR (2015, p. 255).

Sabemos da importância do domínio da linguagem, porém, parece-nos que a sugestão, proposta na figura anterior, está descontextualizada, pois o texto não apresenta delimitação entre o gênero oral e textual, no que se refere ao uso da linguagem. Além disso, parece haver certa limitação em relação à linguagem oral, de modo que, como exposto, a oralidade reduz-se à coloquialidade.

Por fim, no tópico Conclusão há um direcionamento para uma atividade que os alunos deverão "praticar" o que foi abordado neste capítulo.

\section{Conclusão}

No capítulo Intervalo desta unidade, é proposta a apresentação de um seminário que você deverá realizar em grupo. Após a realização da atividade, volte a este capítulo troque ideias com os colegas sobre o que é, para que serve e como se faz um seminário e dê as principais características desse gênero, levando em conta os seguintes critérios: finalidade do gênero, perfil dos interlocutores, suporte ou veículo, tema, estrutura e linguagem.

Figura 6 - Conclusão da unidade.

Fonte: CEREJA; COCHAR (2015, p. 256).

Como percebemos, propõe-se que a partir de um tema central, Saúde na adolescência, os estudantes organizem um seminário em grupo.

\section{Discussão}

A partir da análise do capítulo em questão, notamos a negligência da inclusão dos gêneros orais no LD. Conforme já mencionamos inicialmente, o livro apresenta somente um capítulo referente a gênero oral, 
reduzindo-se, apenas, ao gênero seminário, sendo este, apresentado de forma muito limitada. Além de não haver a orientação da mediação do professor (o capítulo dialoga apenas com o estudante), as atividades aparentam ser mais um roteiro a ser seguido do que o trabalho com o gênero oral formal.

Notamos, também, a fuga do tema sobre o gênero, quando o capítulo faz referência às atitudes do apresentador, bem como, a sugestão dos recursos audiovisuais, que, por mais que sejam elementos relevantes, não se relacionam diretamente com o tema. Nesse sentido, observamos a ausência da exploração do seminário, enquanto gênero oral, pois o mesmo só é apresentado brevemente na apresentação do capítulo.

Também destacamos o reducionismo do tópico conclusão, pois

Gêneros orais no ensino fundamental apenas direciona para uma atividade sem apresentar detalhamento da tarefa, bem como, não sugere a intervenção do professor no desenvolvimento do trabalho, considerando que são discentes do $8^{\circ}$ do ensino básico, que, provavelmente precisariam de auxílio.

Sendo assim, entendemos que o capítulo proposto pelo LD está em desacordo com o que prevê os documentos oficiais, referentes ao ensino de Língua Portuguesa, bem como com a real necessidade da exploração dos gêneros orais no contexto escolar. O capítulo referente ao gênero seminário é apresentado de forma sucinta e roteirizada, sem explorar todas as especificidades de um gênero oral, como a seleção do tema a ser apresentado, o trabalho em grupo, os recursos que podem ser utilizados, bem como a importância da interferência do professor para mediar a atividade.

Se os estudantes dispuserem de um bom auxílio do professor (que traga mais conhecimento a respeito do gênero e oriente as atividades), é possível que os estudantes compreendam, verdadeiramente, as características do gênero e, assim, estarão aptos a desenvolverem-se comunicativamente em diferentes situações formais.

\section{Considerações finais}

Conforme destacamos ao longo do texto, o trabalho com os gêneros orais no contexto escolar ainda é muito negligenciado em relação aos gêneros escritos. Embora os livros didáticos sejam, em geral, a principal ferramenta de apoio ao trabalho do professor, estes não contemplam os gêneros orais em sua totalidade. 
Ana Paula

Elsner

Luane Guerra

Vitorino

148

Nossa análise, ainda que sucinta e restrita a apenas um LD, provoca-nos a reflexão da necessidade do aperfeiçoamento dos materiais didáticos escolares, bem como, confirma-nos que ainda há muito caminho a ser trilhado em relação ao espaço destinado aos gêneros orais na escola básica, inclusive, nos livros didáticos. Quando os materiais didáticos fornecerem completamente as possibilidades de trabalho com os gêneros orais formais, saberemos que estarão contribuindo não só para a formação dos discentes, como também para os docentes, pois, conforme Melo e Cavalcante (2007, p.76), “o passo inicial para o ensino da oralidade é ter clareza sobre as características do oral a ser ensinado e saber até que ponto esses aspectos podem ser objeto de ensino de maneira explícita e consciente".

Por conseguinte, a obrigatoriedade proposta pelos PCN's, em vista dos gêneros orais, infelizmente não corresponde à realidade encontrada no LD contemplado. Sendo assim, este artigo cabe ressaltar que as considerações apresentadas não buscam encerrar os debates em torno do tema, mas sim, levantar discussões que poderão gerar embasamento a outras pesquisas, uma vez que os gêneros orais, no ensino básico, está em constante discussão.

\section{REFERÊNCIAS}

BENTES, A.C. Linguagem oral no espaço escolar: rediscutindo o lugar das práticas e dos gêneros orais na escola. In: MARCURSCHI, B; SUASSUNA, L (Orgs). Avaliação em língua portuguesa: contribuições para a prática pedagógica. - 1 ed., 1 reimp. Belo Horizonte: Autêntica, 2007.

BUENO, L.; ABREU, C. Gêneros orais na universidade: relato de uma experiência com o seminário. Synergies Brésil. 2008.

BUENO, L.; COSTA-HUBES, T. Gêneros orais no ensino. Campinas, São Paulo: Mercado das Letras, 2015.

CEREJA, W. R.; COCHAR, T. Português linguagens, $8^{\circ}$ ano. $9^{\circ}$ ed. Reform. São Paulo: Saraiva, 2015. 
CORACINI, M. J. R. F. O processo de Legitimação do Livro Didático na escola de Ensino Fundamental e Médio: Uma questão de ética. In: CORACINI, Maria José Rodrigues Faria. Interpretação, Autoria e Legitimação do Livro Didático. Campinas, SP: Pontes, 1999, p. 33-43.

CRUZ, W. A. Gêneros orais nos livros didáticos de Língua Portuguesa. Dissertação. - UFRJ, Faculdade de Letras, RJ, 2012.

DOLZ, J.; BEUNO, L. Gêneros orais e gêneros produzidos na interface Gêneros orais escrito-oral: o discurso de formatura no ensino fundamental e sua conno ensino tribuição para o letramento escolar. In: BEUNO, L.; COSTA-HUBES, T. C. fundamental (Orgs.). Gêneros orais no ensino. Campinas, SP: Mercado de Letras, 2015.

HOUAISS. A. Dicionário eletrônico da Língua Portuguesa. Rio de Janeiro: 2009.

LEAL, T. F.; GOIS, S. A oralidade na escola: a investigação do trabalho docente como foco de reflexão. Belo Horizonte: Autentica. 2012.

MARCUSCHI, L. A. Da fala para a escrita: atividades de retextualização. São Paulo: Cortez; 2001.

MELO, C. T. V; CAVALCANTE, M. B. Superando os obstáculos de avaliar a oralidade. In: MARCURSCHI, B; SUASSUNA, L (Orgs). Avaliação em língua portuguesa: contribuições para a prática pedagógica. - 1 ed., 1 reimp. Belo Horizonte: Autêntica, 2007.

PORTAL DO FNDE. Fundo Nacional de Desenvolvimento da Educação. Disponível em: <http://www.fnde.gov.br/http://www.fnde.gov. br/>. Acesso em: 16 de mai. 2018.

PNLD. Programa Nacional do Livro Didático. Guia de livros didáticos ensino fundamental anos finais. 2016.

SILVA, R C. A pertinência da utilização do sistema de avaliatividade como referência em pesquisas sobre recepção de livros didáticos: reflexões teóricas e metodológicas. Letras, Santa Maria, v. 25, n. 50, p. 359-382, jan./jun. 2015. 
SCHNEUWLY, B; DOLZ, J. Gêneros Orais e Escritos na escola. Tradução e organização Roxane Rojo e Glaís Sales Cordeiro. Campinas, SP: Mercado de Letras, 2004.

WITZEL, D. G. Identidade e Livros Didáticos: Movimentos identitários do professor de Língua Portuguesa. 2002. Disponível em: Ana Paula <http://www.ple.uem.br/defesas/pdf/dgwitzel.pdf>. Acesso cinco de Elsner janeiro de 2011.

\section{Luane Guerra}

Vitorino 